\title{
Isolation, Identification and Molecular Detection of Zoonotic Campylobacter jejuni Isolated from Mutton and Beef Samples
}

\author{
Sumedha Bobade*, K. Vijayarani, K. G. Tirumurugaan, \\ A. Thangavelu and S. Vairamuthu \\ Department of Animal Biotechnology, Madras Veterinary College, \\ TANUVAS, Chennai (Tamil Nadu), India \\ *Corresponding author
}

\section{A B S T R A C T}

\section{Keywords}

CCDA, Hip O, MAP, Hippurate, C. jejuni

Article Info

Accepted:

12 October 2020

Available Online:

10 November 2020
Campylobacter species are a leading cause of food-borne disease and C. jejuni highlight the most potential public health impact of Campylobacter contamination by pathogens originating from animals or animal products.. The total of 33meat samples comprising 8 from sheep (5) and goat (3) also 25 beef samples were screened by morphological, biochemical and molecular technique. The isolates were subjected to phenotypic characterization using biochemical test and genotypic characterization. The isolates from chevon (3 out of 3 ) and mutton (2 out of 5) were positive for morphological and biochemical examination. The $20(80 \%)$ beef samples were found to be positive by morphological examination and $12(48 \%)$ isolates showed biochemical reactions positive for C.jejuni. The isolates were subjected to PCR targeting hip O and MAP A genes. The result showed $66.66 \%$ from chevon, $20 \%$ mutton and $20 \%$ isolates from beef samples were found to be positive for C.jejuni. These findings suggest that PCR should be the preferred diagnostic method for detection of Campylobacter in livestock. The good hygienic and manufacturing practices must be followed in the entire food chain to prevent the contamination of food due to microbe which can cause Campylobacteriosis among the consumers.

\section{Introduction}

The pathogenesis of $C$. jejuni is poorly understood as compared to other enteric pathogens (Rizal et al., 2010). Cattle are a major source of food and the cattle industry engages people from farms to processing plants and meat markets, it is plausible that beef-products contaminated with
Campylobacter spp. would pose a significant public health concern (Sanad et al., 2011). The sudden onset of fever, abdominal cramps, and diarrhoea with blood and leukocytes are characteristics of $C$. jejuni infection (Kim et al., 2015). Campylobacter spp. can be transferred from animals to humans by contaminated food of animal origin. Chicken has been recognized as a major source for 
human infection, whereas cattle might also contribute to a lesser extent. Cattle is the second major reservoir for $C$. jejuni (Jonas et $a l ., 2015)$. The consumption of contaminated meat and meat products are responsible for more than $90 \%$ of human infections caused by Campylobacter jejuni (Mikulic et al., 2016). Campylobacteris considered as a principal cause of most important zoonotic food-borne disease in humans for approximately 166 million diarrheal cases and globally 37,600 deaths per year (Oh et al., 2018).

In humans, clinical signs of Campylobacteriosis include diarrhea, abdominal pain, fever, headache, nausea and vomiting. Most of Campylobacter are sporadic and self-limiting, The main recognized sequelae are Guillain-Barré Syndrome (GBS), the Reactive Arthritis (REA) and irritable bowel syndrome (IBS). Thermo tolerant Campylobacter which has a clinical significance due to the consumption of meat and meat products are $C$. jejuni and its closely connected (Mikulic et al., 2016). For more than three decades Campylobacter is pathogen-related causes and significant factor of diarrheal illnesses in human (Magana et al., 2017). This zoonotic infection is of great public health concern, with meats known as the major risk factor (Carron et al., 2018). Campylobacter spp. is a zoonotic bacterium and cause of human gastroenteritis worldwide and main symptom is diarrhea (Hlashwayo et al., 2020).

Campylobacter is difficult to isolate, grow and identify. Only Campylobacter jejuni can be routinely identified with phenotypic markers, and commercial systems may misidentify non-jejuni species (Fitzgerald et $a l .$, 2016). Campylobacter poses an important risk for humans through shedding of the pathogen in livestock waste and contamination of water sources, environment, and food by colonization of different animal reservoirs (Gahamanyi et al., 2020). The reservoir and source of human campylobacteriosis is primarily considered to be poultry, but also other such as ruminants, pets and environmental sources are related with infection burden (Maesaar et al., 2020).There is a high incidence of Campylobacter species in meat carcasses, suggesting these to be a reservoir of Campylobacteriosis agents, and consumption of undercooked meats is a potential health risk to consumers (Igwaran and Okoh, 2020).

The major transmission routes of Campylobacteriosis in humans are consumption of contaminated or undercooked meat. Despite the size of the livestock and meat industry in India, little is known about the Campylobacteriosis as zoonotic foodborne pathogen. Hence this study was attempted to detect the presence of $C$. jejuni using morphological, biochemical and PCR technique and compare these techniques for detection among different sources from animal origin.

\section{Materials and Methods}

\section{Collection of samples}

A total of (8) meat sample of Sheep (5) and Goat (3) meat collected from retail outlet and beef (25) samples from slaughter house were collected using sterile containers and transported immediately to the laboratory under cold conditions for microbiological analysis.

\section{Processing of samples}

The isolation was performed according to Man (2011) and the isolates were identified by biochemical tests as described by (Fitzgerald and Nachamkin, 2007 and Lastovica and Allos, 2008). The reference strain Campylobacter jejuni (ATCC33291) was used as standard for PCR. 


\section{Phenotypic characterization}

\section{Morphological examination}

Sample was enriched in modified Charcoal Cefoperazone Deoxycholate (mCCDA) broth (Hutchinson and Bolton, 1984) with CCDA supplement (FD 135) under microaerophillic conditions (candle jar method) by using internal gas generation system using (Microaerophilic gas pack CampyPack-BD oxoid).

\section{Biochemical test}

The isolates were identified based on their morphological and biochemical tests .Suspected colonies were sub-cultured and confirmed by catalase, oxidase, nitrate and hippurate hydrolysis, Ninhydrintest, $\mathrm{H}_{2} \mathrm{~S}$ production for confirmation as $C$. jejuni.

\section{Molecular confirmation of Campylobacter jejuni}

The biochemically identified isolates were further employed for molecular confirmation as $C$. jejuni by polymerase chain reaction amplifying specific target gene using speciesspecific oligonucleotide primers. DNA was extracted by Phenol-Chloroform extraction method and the DNA concentration was quantified by nanodrop and stored at $-20^{\circ} \mathrm{C}$ until further processing.

Genotypic confirmation of isolates by polymerase chain reaction for Hip $O$ gene and MAP Agene

Polymerase chain reaction was carried out using primers for species specific genes. The PCR was performed in a thermal cycler (Applied Biosystem). The hipO gene region is the hippuricase gene, specific for $C$. jejuni. Primers for hipO gene specific identification were designed using the gene sequences of
C.jejuni based on the sequences available in the GenBank. The isolates were confirmed by PCR using designed primers in the study for hipO gene as forward primer (5TTCCATGACCACCTCTTCC-3) and reverse primer (5-CTACTTCTTTATTGCTTGCTGC $-3)$.

The primers used for amplification of MAP A gene were forward primer (5CTATTTTATTTTTGAGTGCTTGTG-3) and reverse primers (5-GCTTTATTTGCC ATTTGTTTTATTA-3) (Khoshbakht et al., 2015).

The PCR reactions were performed in $25 \mu 1$ reaction mixture, containing $12.5 \mu \mathrm{l}$ PCR master mix (2X-Ampliqon), $1 \mu 1$ of each primer of a $10 \mu \mathrm{M}$ primer concentration, $1 \mu \mathrm{l}$ $\mathrm{MgCl}_{2}(25 \mathrm{mM}), 3 \mu \mathrm{l}$ template DNA and $6.5 \mu \mathrm{l}$ nuclease-free water making a total volume of $25 \mu \mathrm{l}$. The amplification conditions consisted of initial denaturation at $94{ }^{\circ} \mathrm{C}$ for $3 \mathrm{~min}, 35$ cycles with denaturation at $94{ }^{\circ} \mathrm{C}$ for $1 \mathrm{~min}$, annealing at $53^{\circ} \mathrm{C}$ for $\mathrm{HipO}$ gene for $1 \mathrm{~min}$, and extension at $72{ }^{\circ} \mathrm{C}$ for $1 \mathrm{~min}$, followed by a final extension at $72{ }^{\circ} \mathrm{C}$ for $5 \mathrm{~min}$ respectively (Al Amri et al., 2007) .The annealing temperature for MapA gene was optimized as $52{ }^{\circ} \mathrm{C}$ for $1 \mathrm{~min}$ (Khoshbakht $e t$ $a l ., 2015$ ). The DNA from $C$. jejuni (ATCC 33291) was included as positive control for PCR identification of the isolates and the master mix without sample DNA used as negative control. The amplified products were observed and photographed using gel documentation System (Applied Biosystems).

\section{Results and Discussion}

Campylobacter spp. is a major cause of gastroenteritis, there is an urgent need to control these pathogens with zoonotic and public health point of view. The Campylobacter species are difficult to isolate but the results from inoculation studies 
showed that plates with charcoal had a better recovery rate than other media used for isolation. Modified blood free Charcoal cefoperazone deoxycholate agar is commonly used worldwide (Bolton et al., 1984; Hutchinson and Bolton, 1984). In current study all samples showed growth on mCCDA agar plates. On selective agar, Blood free modified charcoalcefoperazone deoxycholate (mCCDA), colonies were found to be typical grey/white or creamy grey in colour, smooth, glistening, and convex with entire edges and moist in appearance, dew drop with the tendency to spread with sticky nature were confirmed phenotypically as Campylobacter. The suspected colonies were examined for morphological characteristics, motility, Gram's staining. Campylobacter species are Gram negative rods with characteristically curved, spiral, or S-shaped cells. The overall incidence of Campylobacter was found to be ( 3 out of 3 ) in chevon and ( 2 out of 5) mutton also $20(80 \%)$ in beef by morphological examination (Table 1 and 2).

\section{Biochemical characterization}

The isolates were processed for phenotypic characterization and identified by biochemical tests, viz. oxidase, catalase, indoxyl acetate hydrolysis tests and $\mathrm{H}_{2} \mathrm{~S}$ production in triple sugar iron test. In current investigation of eight samples from mutton and chevon processed five isolates showed positive reaction for all biochemical test. The Twelve isolates from beef sampled showed positive reaction for biochemical tests and tentatively confirmed as Campylobacter. The test for hippurate hydrolysis is critical for separation of Campylobacter jejuni and C. coli strains. Glycine and benzoic acid are formed when hippurate is hydrolyzed by $C$. jejuni (Morris et al., 1985). Out of the 46 isolates screened, 33 were found positive for hippurate hydrolysis and were classified as $C$. jejuni (Kumar et al., 2015). In current study 5 isolates from chevon and mutton and 12 isolates from beef were confirmed as C.jejuni on basis of hippurate hydrolysis test.

Two samples from chevon and one from beef were positive for $\mathrm{H}_{2} \mathrm{~S}$ production. The most of the samples were negative for $\mathrm{H}_{2} \mathrm{~S}$ production C. jejuni biotype 2 strains are $\mathrm{H}_{2} \mathrm{~S}$ positive, whereas $C$. jejuni biotype 1 strains are $\mathrm{H}_{2} \mathrm{~S}$ negative (Penner, 1988).In this studythree isolates were positive for $\mathrm{H}_{2} \mathrm{~S}$ production belong to biotyope 2 while 14belong to biotype 1 of $C$.jejuni.

\section{Genotypic characterization}

The isolates were confirmed by polymerase chain with species specific primers for $H I P O$ and MAP A gene. The size of PCR product for Hip $\mathrm{O}$ gene was $270 \mathrm{bp}$ and the size of the PCR product for MAP A gene was $589 \mathrm{bp}$. Three isolates (two from chevon and one from mutton) as well as five from beef samples showed specific amplification and confirmed as $C . j e j u n i$.

\section{Incidence of Campylobacter jejuni in chevon mutton and beef}

Among meat samples processed, the prevalence of Campylobacter was recorded in raw beef $(10.9 \%)$ and raw mutton $(5.1 \%)$. The study reported that the prevalence of Campylobacter spp. was significantly higher in the food commodities, which included raw/undercooked ingredients (Hussai et al., 2007). A total of 183 chevon, and 42 carabeef were processed and samples showed characteristic colonies on mCCDA plates. The prevalence rate of $7.6 \%$ was recorded in chevon. None of the isolates were recovered from beef samples. Most of the obtained isolates were classified as $C$. jejuni indicating that the $C$. jejuni was the most commonly found species while in current study five beef samples were confirmed as C. jejuni. The 183 
chevon samples processed, 14 (7.6\%) were reported as Campylobacter 10 were identified to be $C$. jejuni through molecular means (Monika et al., 2016), while in our study, 5 $(62.5 \%)$ from muton and chevon samples were found to be positive by molecular identification using species specific primer. Among the 853 livestock faecal samples, Campylobacter were detected by culture in 106 samples (12\%); 72 samples $(68 \%)$ tested positive for $C$. jejuni (Osbjer et al., 2016). A total of Mutton $(n=100)$ samples were collected from different open markets of Kolkata cityCampylobacter spp. was detected $64 \%$ of mutton meat samples. The most prevalent species recovered from samples was Campylobacter jejuni with $58.8 \%$ of the isolates confirmed (Sharma et al., 2016) while lower incidence was recorded from this study.

Rahimi et al., (2010) conducted a study to determine the prevalence of Campylobacter spp. isolated from retail raw meats in Iran. A total of $(n=190)$ beef, $(n=225)$ lamb, and ( $n$ $=180)$ goat raw meat samples were purchased from randomly selected retail outlets and were evaluated for the presence of Campylobacter spp. The highest prevalence of Campylobacter spp. was found in lamb meat $(12.0 \%)$, followed by goat meat $(9.4 \%)$, beef meat $(2.4 \%)$. The most prevalent Campylobacter spp. isolated from the meat samples was Campylobacter jejuni $(84.0 \%)$ in accordance with current study. A total of 200 samples consisting of 100 meat and 100 liver surface swabs were collected from 47 lamb and 53 goat kid carcasses at 23 retail markets in Northern Greece and 125 Campylobacter isolates were recovered from 32 meat surfaces (32\%) and 44 liver surfaces $(44 \%)$ and $C$. jejuni $(40.8 \%)$ detected species by multiplex polymerase chain reaction (Lazou et al., 2014).The overall prevalence of Campylobacter in different sample groups was $41.2 \%, 37.2 \%, 23.7 \%$, and $35.1 \%$ for goat meat, goat stomachs, RTE goat skewers, and goat faecal samples, respectively. C. jejuni was isolated in $10.1 \%$ samples (Mpalang et al., 2014). Pallavi and Kumar (2014) studied the prevalence of Campylobacter species in foods of animal origin. A total of 50 chevon were collected from retail meat markets, slaughter houses and analyzed for isolation biochemical characterization and confirmed by polymerase chain reaction. The prevalence of Campylobacter spp. in chevon 6\% was observed while in current study highest incidence rate was observed.

The study to isolate and detect Campylobacter species in meat samples, including mutton offals, beef, beef offals the samples were subjected to both traditional culture on modified charcoal cefoperazone deoxycholate agar (mCCDA) plates and PCR techniques. From culture, a total of 845 presumptive isolates were obtained, of which $28.40 \%$ (208/845) were identified as $32.5 \%$ (208/640) were obtained from retail markets, $15.17 \%$ (22/145) from butcheries, and 16.67\% (10/60) from open markets. Campylobacter presumptive isolates from mutton sample 4 $(44.44 \%)$ and $30(33.71 \%)$ from beef were identified as genus Campylobacter. These were then characterised into species level, of which the prevalence rate of $C$. jejuni was observed (16.66\%) (Igwaran and Okoh, 2020). Campylobacter detection and prevalence calculations estimate in $17.8 \%$ (95\% CI 12.6-24.5) of 2907 goat samples; $12.6 \%$ (95\% CI 8.4-18.5) of 2382 sheep samples; and $12.3 \%$ (95\% CI 9.5-15.8) of 6545 cattle samples suggested that meat and organs were significantly less likely to be contaminated than gut samples (Thomas et al., 2020).The overall prevalence of Campylobacter for ovine trim based on PCRdetection was $33 \%$ (39 out of 120 samples) with prevalence for hogget, lamb and mutton carcass trim of $56 \%$ (28out of 50), 11\% (4 out of 35 ) and $20 \%$ (7 out of 35), respectively (Rivas et al., 2020) in conformity with our study (Fig. 1). 
Table.1 Result of biochemical test of $C$. jejuni isolated from different sources

\begin{tabular}{|c|c|c|c|c|c|c|c|c|c|c|}
\hline \multirow{3}{*}{$\begin{array}{l}\text { Sr. } \\
\text { No. }\end{array}$} & \multirow[t]{3}{*}{ Samples/source } & \multirow{3}{*}{$\begin{array}{l}\text { Samples } \\
\text { Examined }\end{array}$} & \multirow{3}{*}{$\begin{array}{l}\text { Isolates } \\
\text { showed } \\
\text { growth on } \\
\text { mCCDA } \\
\text { agar }\end{array}$} & \multicolumn{7}{|c|}{ Biochemical test } \\
\hline & & & & \multirow[t]{2}{*}{ Catalse } & \multirow[t]{2}{*}{ oxidase } & \multirow[t]{2}{*}{ nitrate } & \multirow[t]{2}{*}{ Glysin } & \multirow[t]{2}{*}{ Ninhydrin } & \multicolumn{2}{|c|}{$\mathrm{H}_{2} \mathrm{~S}$ production } \\
\hline & & & & & & & & & Positive & Negative \\
\hline 1 & Mutton (M1-M5) & 5 & 5 & 2 & 2 & 2 & 2 & 2 & 0 & 2 \\
\hline 2 & Chevon (M6-M8) & 3 & 3 & 3 & 3 & 3 & 3 & 3 & 2 & 1 \\
\hline 3 & $\begin{array}{l}\text { Beef } \\
(\mathrm{BF} 1-\mathrm{BF} 25)\end{array}$ & 25 & 25 & 12 & 12 & 12 & 12 & 12 & 1 & 11 \\
\hline
\end{tabular}

M-sheep and goat meat BF-beef samples

Table.2 Morphological, phenotypic and genotypic characterization of $C$. jejuni isolates

\begin{tabular}{|l|l|c|c|c|}
\hline Sr.No. & Samples/source & $\begin{array}{c}\text { Morphological } \\
\text { Characterization }\end{array}$ & $\begin{array}{c}\text { Phenotypic } \\
\text { Characterization }\end{array}$ & $\begin{array}{c}\text { Genotypic } \\
\text { Characterization }\end{array}$ \\
\hline $\mathbf{1}$ & Mutton & $\mathbf{2 ( 4 0 \% )}$ & $\mathbf{2 ( 4 0 \% )}$ & $\mathbf{1 ( 2 0 \% )}$ \\
\hline $\mathbf{2}$ & Chevon & $\mathbf{3 ( 1 0 0 \% )}$ & $\mathbf{3}(\mathbf{1 0 0 \%})$ & $\mathbf{2 ( 6 6 . 6 6 \% )}$ \\
\hline $\mathbf{3}$ & Beef & $\mathbf{2 0}(\mathbf{8 0 \%})$ & $\mathbf{1 2}(\mathbf{4 8 \%})$ & $\mathbf{5 ( 2 0 \% )}$ \\
\hline
\end{tabular}

Figure.1 Comparative result of phenotypic and genotypic study of $C$. jejuni

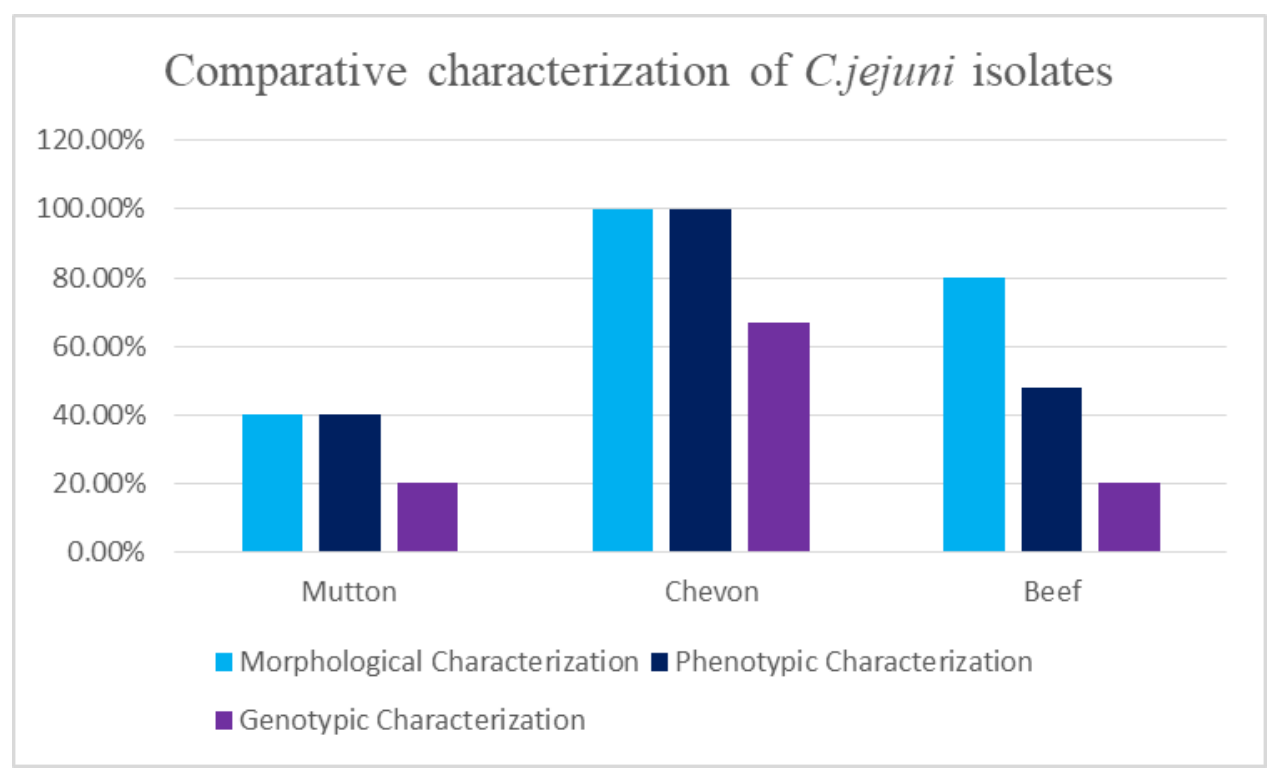

It is concluded in this study, we were able to isolates, identify and study incidence of Campylobacter jejuni in samples obtained from retail market from chevon and meat and beef with high incidence rate. The current study reveals that consumption of 
undercooked meat products and crosscontamination during food handling and preparation must be avoided to ensure food safety at home and in the food service industry. The role of animal sources should not be overlooked with regard to public health, and animal products and consumer markets should be frequently inspected to minimize the risk of infection. As microbial food safety is an essential public health issue, the sincere efforts are needed to create awareness among the people about the hazards of foodborne diseases. Incidence data from the current study will be helpful to public health professionals to identify high risk food items sold in the shops.

\section{References}

Bolton, F. J., D. N. Hutchinson and Coates D., (1984). Blood-free selective medium for isolation of Campylobacter jejuni from feces. J Clin Microbiol. 1984 Feb; 19(2): 169-171.

Carron, M., Y.M. Chang, K. Momanyi, J. Akoko, J. Kiiru, J. Bettridge, G. Chaloner, J. Rushton, S. O'Brien, N. Williams, E. M. Fèvre and Hasler B. (2018). Campylobacter, a zoonotic pathogen of global importance: Prevalence and risk factors in the fast evolving chicken meat system of Nairobi, Kenya. PLoSNegl Trop Dis 12(8): e0006658.

Fitzgerald, C., and Nachamkin I., (2007). Campylobacter and Arcobacter, p. 933946. In P. R. Murray, E. J. Baron, J. H. Jorgensen, M. L. Landry, and M. A. Pfaller (ed.), Manual of clinical microbiology, 9th ed. ASM Press, Washington, DC.

Fitzgerald, C., M. Patrick, A. Gonzalez, J. Akin, C.R. Polage, K. Wymore, L. Gillim-Ross, K. Xavier, J. Sadlowski, J. Monahan, S. Hurd, S., Dahlberg R. Jerris, R., Watson, M. Santovenia, D. Mitchell, C. Harrison, M. Tobin-
D'Angelo, M., DeMartino, M. Pentella, J. Razeq, C. Leonard, C. Jung, R. Achong-Bowe, Y. Evans, D. Jain, B. Juni, F. Leano, T. Robinson, K. Smith, R.M. Gittelman, C. Garrigan and Nachamkin I., (2016). Multicenter Evaluation of Clinical Diagnostic Methods for Detection and Isolation of Campylobacter spp. from Stool. J Clin Microbiol. 54(5):1209-15.

Gahamanyi, N., L. E. G. Mboera, M. I. Matee, D. Mutangana and Komba E. V. G. (2020). Prevalence, Risk Factors, and Antimicrobial Resistance Profiles of Thermophilic Campylobacter Species in Humans and Animals in Sub-Saharan Africa: A Systematic Review. Int. J. icrobiol. 2020:1-8.

Hlashwayo, D.F., B. Sigaúque andBila C.G., (2020). Epidemiology and antimicrobial resistance of Campylobacter spp. in animals in Sub-Saharan Africa: A systematic review. Heliyon. 2020 Mar 9; 6(3): e03537. doi: 10.1016/j.heliyon.2020.e03537.

Hussaina, I. M. S. Mahmooda, M. Akhtarb and Khan A. (2007). Prevalence of Campylobacter species in meat, milk and other food commodities in Pakistan. Food Microbiology, 24 (2007): 219-222.

Hutchinson, D. N. and Bolton F. J. (1984). Improved blood-free selective medium for the isolation of Campylobacter jejuni from fecal specimens. J. Clin. Pathol. 37: 956-957.

Igwaran A. and Okoh A. I. (2020). Campylobacteriosis Agents in Meat Carcasses Collected from Two District Municipalities in the Cape Province, South Africa. Foods. 9(2): 203.

Jonas, R., S. Kittl, G., Overesch and Kuhnert P. (2015). Genotypes and antibiotic resistance of bovine Campylobacter and their contribution to human campylobacteriosis. Epidemiol. Infect. 143: 2373-2380. 
Khoshbakht R, M. Tabatabaei, S. Hosseinzadeh, H. S.Askiand Seifi S.,(2015). Genetic Characterization of Campylobacter jejuni and $C$. coli Isolated from Broilers Using flaA PCRRestriction Fragment Length Polymorphism Method in Shiraz, Southern Iran. Jundishapur J Microbiol. 8(5): e18573.

Kim J.C. E. Oh, J. Kim and Jeon B. (2015). Regulation of oxidative stress resistance in Campylobacter jejuni, a microaerophilic foodborne pathogen. Front. Microbiol. 6: 751.

Kumar, S. M., T.P. Ramees, H. Dhanze, S. Anjay, Gupta, Z.B. Dubal, M. Sivakumar and A. Kumar, 2015. Occurrence of Thermophilic Campylobacter in Foods of Animal Origin, Animal Faeces and Human Stool. J. Vet. Pub. Hlth . 13 (2): 105109.

Lastovica, A. J. and Allos, M. B. (2008). Clinical significance of Campylobacter and related species other than Campylobacter jejuni and Campylobacter coli. In Campylobacter, 3rd edn, eds. Nachamkin, I.; Szymanski, C. M.; Blaser, M. J. 123-50. Washington, D.C.: American Society for Microbiology.

Lazou, T., C. Dovas, K. Houf, N. Soultos and Iossifidou E. (2014). Diversity of Campylobacter in retail meat and liver of lambs and goat kids. Foodborne Pathog Dis. 11(4): 320-8.

Maesaar, M., T. Tedersoo, K. Meremae and Roasto M. (2020). The source attribution analysis revealed the prevalent role of poultry over cattle and wild birds in human campylobacteriosis cases in the Baltic States. PLoS ONE 15(7): e0235841.

Magana M., S. Chatzipanagiotou, A. R. Burriel and Ioannidis A., (2017). Inquiring into the gaps of
Campylobacter surveillance methods. Vet. Sci. 4(36):1-14.

Man, S.M., (2011). The clinical importance of emerging Campylobacter species. Nat. Rev. Gastroenterol. Hepato. 8: 669-685.

Mikulic, M., A. Humski, B. Njari, M.,M. Ostovic, S. Duvnjak and Cvetnic Z., (2016). Prevalence of Thermotolerant Campylobacter spp. In Chicken Meat in Croatia and Multi locus Sequence Typing of a Small Subset of Campylobacter jejuni and Campylobacter coli Isolates. Food Technol. Biotechnol. 54(4): 475-481.

Monika, A., A.K. Upadhyay, S.P. Singh, P.K. Singh, Ipshita and Kumar A.,(2016). Isolation, epidemiological and molecular characterization of Campylobacter from Meat Int. J. Innovative Res. and Dev. 5(1):246-248.

Morris, G.K., M. R. el Sherbeeny, C.M. Patton, H. Kodaka, G. L. Lombard, P. Edmonds, D. G. Hollis, and Brenner D. J. (1985). Comparison of four hippurate hydrolysis methods for identification of thermophilic Campylobacter spp. J Clin Microbiol. 22(5): 714-718.

Mpalang, R.K., R. Boreux, P. Melin, K. Akir Ni Bitiang, G. Daube andMol P. D., (2014). Prevalence of Campylobacter among goats and retail goat meat in Congo. J Infect DevCtries. 2014 Feb 13; 8(2): 168-75. doi: $10.3855 /$ jidc. 3199 . PMID: 24518626.

Oh E., Katelyn, Andrews J. and Jeon B., (2018). Enhanced biofilm formation by ferrous and ferric iron through oxidative stress in Campylobacter jejuni. Front Microbiol. 2018; 9 (1204): 1-9.

Osbjer K., E. Tano, L. Chhayheng, A.O. MacKwashie, L.L. Fernstrom, P. Ellstrom, S. Sokerya, C. Sokheng, V. Mom, K. Chheng, S. San, H. Davun, S. Boqvist, H. Rautelin and Magnusson U. (2016). Detection of Campylobacter in human and animal field samples in Cambodia. 
APMIS, 124: 508-515.

Pallavi, and A. Kumar, 2014. Prevalence and antibiotic resistance pattern of Campylobacter species in foods of animal origin. Vet. World. 7(9): 681684.

Penner J.L. (1988). The Genus Campylobacter: a Decade of Progress. Clinical microbiology reviews. 1(2): 157-172.

Rahimi, E., A. Chakeri, and Tajbakhsh E., (2010). Prevalence and antimicrobial resistance of Campylobacter species isolated from raw camel, beef, lamb, and goat meat in Iran. Foodborne Pathog Dis. 7(4): 443-7.

Rivas, L., P.Y. Dupont, B. Gilpin and Withers H., (2020). Prevalence and genotyping of Campylobacter jejuni and coli from ovine carcasses in New Zealand. Journal of Food Protection. DOI: 10.4315/jfp20-220.

Rizal, A., A. Kumar and Vidyarthi A.S., (2010). Prevalence of pathogenic genes in Campylobacter jejuni isolated from poultry and human. I. J. of Food Safety.12: 29-34.

Sanad, Y.M., I.I. Kassem., M. Abley, W. Gebreyes, J.T. LeJeune and Rajashekaraet G. (2011). Genotypic and Phenotypic Properties of CattleAssociated Campylobacter and Their Implications to Public Health in the USA. PLoS ONE 6(10): e25778.

Sharma, K., U. K. Chattopadhyay and Naskar K. (2016). Prevalence of Campylobacter species in raw meat samples sold in open markets of Kolkata city. Int. J. Agri. Environ. Biotechnol. 9(4): 535.

Thomas, K.M., W.A. de Glanville, G.C. Barker, J. Benschop, J.J. Buza, S. Cleaveland, M.A. Davis, N.P. French, B.T. Mmbaga, G. Prinsen, E.S. Swai R.N. Zadoks and Crump J.A.,(2020). Prevalence of Campylobacter and Salmonella in African food animals and meat: A systematic review and metaanalysis. Int J Food Microbiol. 16; 315: 108382.

\section{How to cite this article:}

Sumedha Bobade, K. Vijayarani, K.G. Tirumurugaan, A. Thangavelu and Vairamuthu, S. 2020. Isolation, Identification and Molecular Detection of Zoonotic C.jejuni Isolated from Mutton and Beef Samples. Int.J.Curr.Microbiol.App.Sci. 9(11): 1884-1892.

doi: https://doi.org/10.20546/ijcmas.2020.911.223 